\title{
Spreminjanje prepričanj učiteljev o samoevalvaciji šole ter vpliv na vedenje učiteljev in dosežke učencev
}

\author{
Alenka Hauptman* \\ Državni izpitni center
}

\begin{abstract}
Povzetek: Namen raziskave, kije predstavljena vprispevku,jebilougotoviti, ali lahko različninačini spodbujanja samoevalvacije na šoli vplivajo na spreminjanje prepričanj učiteljev o samoevalvaciji, pa tudi na njihovo vedenje v razredu ter na dosežke učencev. Samoevalvacija je v slovenskih šolah namreč zakonsko določena, vendar pa ni enotnih navodil o načinih izvedbe, pa tudi ne sistematičnih raziskav o njeni učinkovitosti. V raziskavi je sodelovalo 111 učiteljev 4. razreda iz 59 slovenskih šol ter 2153 njihovih učencev. Raziskava je bila zasnovana kot eksperiment s tremi skupinami šol in dvema ločenima preverjanjema, vključeno pa je bilo tudi preverjanje trajnosti sprememb prepričanj in vedenja učiteljev. Skupine smo ločili glede na aktivnosti samoevalvacije; prva skupina je bila kontrolna, drugi dve pa smo ločili glede na intenzivnost spodbujanja samoevalvacije. Od učiteljev smo pridobili podatke o njihovih stališčih glede samoevalvacije ter o njihovem vedenju v razredu, od učencev pa, poleg podatkov o vedenju njihovih učiteljev, tudi dosežke pri matematiki in naravoslovju na začetku in koncu šolskega leta. Razlike med skupinami smo pričakovali predvsem na ravni prepričanj učiteljev o samoevalvaciji, pa tudi v vedenju učiteljev ter dosežkih učencev. Rezultati kažejo, da so prepričanja precej stabilna, saj je za spremembo potrebno veliko časa. V raziskavi nismo uspeli dokazati vpliva spodbujanja procesa samoevalvacije na spreminjanje prepričanj, kar je zelo verjetno posledica omejitev raziskave. Sprememba prepričanj je osnova za spreminjanje vedenja in dosežkov, vendar pa se to zgodi v daljšem časovnem okviru.
\end{abstract}

Ključne besede: šole, samoevalvacija, učitelji, prepričanja učiteljev, učna uspešnost

\section{Changing teacher's beliefs about school self-evaluation and the impact on teacher behaviour and student achievement}

\author{
Alenka Hauptman \\ National Examinations Centre, Ljubljana, Slovenia
}

\begin{abstract}
The purpose of the present study was to examine if different ways of promoting school self-evaluation had an effect on changing teachers' beliefs about school self-evaluation, on their behaviour in the classroom and on student achievement. Although school self-evaluation in Slovenian primary schools is legally required; there are no uniform instructions about using it or even systematic research on its effectiveness. Our sample included 111 fourth grade teachers from 59 Slovenian primary schools and their 2153 students. The study was designed as an experimental study with three groups of schools and two separate measurements. Durability of changes in beliefs and behaviour of teachers was also included. Groups of schools differed on activities of school self-evaluation; the first group of schools was the control group, the other two were separated according to intensity of promoting school self-evaluation. The data were gathered from teachers and students. Teachers were asked about their beliefs of school self-evaluation and behaviour in the classroom. From students we gathered data about their achievement in mathematics and science at the beginning and end of school year and data about their teachers' behaviour in the classroom. Differences between the groups of schools were expected mainly at the teachers' beliefs about school selfevaluation and as well on teacher behaviour and student achievement. The results showed that teachers' beliefs are fairly stable, and a lot of time is needed to achieve changes. In our research we failed to prove the impact of promoting school selfevaluation on changing teachers' beliefs, which is very likely the result of research limitations. Change in beliefs is the basis for changing behaviour and achievement, but this happens over a longer timeframe.
\end{abstract}

Key words: schools, self-evaluation, teachers, teacher beliefs, school self-evaluation, academic achievement

${ }^{\bar{*}}$ Naslov/Address: Alenka Hauptman, Državni izpitni center, Ob železnici 16, 1000 Ljubljana; e-pošta: alenka.hauptman@gmail.com

Članek je licenciran pod pogoji Creative Commons Attribution 4.0 licence. / The article is licensed under a Creative Commons Attribution 4.0 International License. 


\section{(Samo)evalvacija}

Evalvacija pomeni sistematično zbiranje in oceno podatkov, ki zagotavljajo koristno povratno informacijo o predmetu preučevanja, npr. o kurikulu, programu, osebah, dejavnostih ipd. (Mažgon, 2010; Poljanšek in Bucik, 2002). Osnovni namen evalvacije organizacije naj bi bil s pomočjo empirično dobljenih in čim bolj objektivno zbranih podatkov vplivati na odločanje, oblikovanje pravil in načina delovanja organizacije (Poljanšek in Bucik, 2002).

Zunanja evalvacija omogoča izdelavo povratne informacije za zunanje uporabnike in je največkrat primerjalne narave. Zunanjo evalvacijo vodijo in izvajajo zunanje organizacije. Notranja evalvacija pa neposredno vključuje udeležence $\mathrm{v}$ programu in je namenjena notranjemu ugotavljanju in zagotavljanju kakovosti. A. Poljanšek in Bucik (2002) opredeljujeta samoevalvacijo kot vrsto notranje evalvacije, ki jo izvaja uporabnik sam, MacBeath in McGlynn (2006) pa notranjo evalvacijo uporabljata kot sinonim za samoevalvacijo. Ta ni uporabljena le v individualnem, ampak tudi v skupinskem smislu.

Samoevalvacijo v vzgojno-izobraževalni organizaciji natančneje opredeljujejo Tiana in sodelavci (1999, v Musek Lešnik in Bergant, 2001) kot »... vrsto notranje evalvacije, pri kateri strokovnjaki, ki so nosilci in izvajalci osnovnega programa in storitev organizacije (učitelji in vodstvo), izvajajo evalvacijo svoje lastne organizacije (šole)" (str. 9). Tudi če pri samoevalvaciji sodelujejo zunanji strokovnjaki in svetovalci, gre še vedno za notranjo evalvacijo, saj nosi vso odgovornost za samoevalvacijo in njeno izvedbo organizacija oziroma njena skupina za samoevalvacijo (Musek Lešnik in Bergant, 2001).

Vsem udeležencem, vodstvu in zaposlenim $\mathrm{v}$ organizaciji mora biti jasno, da je namen samoevalvacije ugotoviti in zagotoviti (dvigniti) kakovost, in ne kaznovati manj kakovostnega dela. Le tako bo samoevalvacija uspešna (Musek Lešnik in Bergant, 2001). Pomemben pa je tudi odnos do samoevalvacije, saj je eden izmed predpogojev za uspešno samoevalvacijo doseganje zavedanja, da je samoevalvacija smiselna in koristna aktivnost (Vanhoof, Van Petegem in De Maeyer, 2009).

V Sloveniji je samoevalvacija že uveljavljen in pogosto uporabljen postopek, saj so šole v Sloveniji zakonsko odgovorne za izvajanje samoevalvacije (Zakon o spremembah in dopolnitvah ZOFVI, 17. člen, 2008). Kljub zakonski odgovornosti pa šole nimajo natančnejših navodil, kako naj samoevalvacijo izvajajo.

\section{Prepričanja učiteljev}

Preučevanje prepričanj je v zadnjih dveh desetletjih postalo zelo pomembno področje znotraj pedagoškopsihološkega konteksta. Harvey (1986, v Fang, 1996) meni, da teorije in prepričanja tvorijo pomemben del splošnega znanja učiteljev, na osnovi katerega učitelji zaznavajo, procesirajo in se odzivajo na informacije v razredu. Pajares (1992) piše tudi o velikem vplivu prepričanj učiteljev na delo v razredu.
Prepričanja so dokaj nespremenljiva, ko pa se spremenijo, se to ne zgodi $\mathrm{z}$ argumentom ali vzrokom, ki bi vplival na spremembo, temveč pride do celostnega preobrata (Nespor, 1987). Hattie (2009) V svoji metaanalitični študiji ugotavlja, da imajo učitelji že ob vstopu na študij precej definirana prepričanja o načinih poučevanja ter o tem, kaj deluje in kaj ne. Posner in dr. (1982, v Pajares, 1992) menijo, da morajo biti posamezniki nezadovoljni z obstoječimi prepričanji in da morajo biti nova prepričanja razumna in verjetna, preden pride do spremembe. Woolfolk Hoy, Davis in Pape (2006) pa menijo, da učitelji spremenijo svoja prepričanja, če ta postanejo eksplicitna, če začnejo dvomiti vanje ali če so izpostavljeni močnim alternativnim pojmovanjem. Najprimernejše okoliščine za spreminjanje stališč so takšne, ki niso ogrožajoče (Middleton, 2002, v Woolfolk Hoy idr., 2006). Programi za razvoj osebja na šolah so običajno neuspešni pri spreminjanju prepričanj in stališč. Več uspeha imajo običajno določene tehnike, za katere nam uspe prepričati učitelje, da jih vsaj poskusijo uporabiti (Guskey, 1986).

Tudi v okviru samoevalvacije je odnos oziroma stališče do samoevalvacije zelo pomemben kriterij uspešnosti njene izvedbe. Samoevalvacija lahko deluje le, če imajo člani tima pozitiven odnos do nje (MacBeath, 1999). Obstajajo pa indikatorji, da odnos do samoevalvacije na splošno ni pozitiven ter da je $\mathrm{v}$ šoli premalo zavedanja o ciljih in uporabi samoevalvacije (Schildkamp, 2007, v Vanhoof idr., 2009). Vanhoof in sodelavci (2009) so v svoji raziskavi ugotovili, da je splošen odnos do samoevalvacije relativno pozitiven, vendar pa samoevalvacija ni priljubljena. Kljub temu pa so v raziskavi udeleženci izrazili, da verjamejo $\mathrm{v}$ zmožnosti samoevalvacije in imajo pozitivna pričakovanja do samoevalvacije.

\section{Vedenje učiteljev ( $v$ odnosu do prepričanj in samoevalvacije)}

Kot smo že omenili, Pajares (1992) piše o pomembnem vplivu prepričanj učiteljev na njihovo delo v razredu. Nespor (1987) pravi, da imajo prepričanja veliko večji vpliv kot znanja na to, kako posameznik organizira in definira naloge in probleme in so boljši napovednik posameznikovega vedenja. J. Hunzicker (2004) meni, da je ključ do spreminjanja vedenja učitelja v razredu spreminjanje njihovih prepričanj, kar pa ni enostavno delo, saj nekateri učitelji potrebujejo za spremembo več mesecev ali celo let. Woolfolk Hoy in sodelavci (2006) menijo, da reforme in izobraževalni programi, katerih namen je spremeniti prepričanja učiteljev, lahko ogrozijo njihove obstoječe zaznave o sebi kot učiteljih. Zato učitelji potrebujejo številne priložnosti, da uskladijo nasprotja med novimi in obstoječimi prepričanji in vedenjem (Pirc, 2010).

Tudi uporaba samoevalvacije lahko vpliva na spremembo vedenja učiteljev (Davies in Rudd, 2001, v Schildkmap, Visscher in Luyten, 2009). Schildkamp in sodelavci (2009) so v svoji raziskavi ugotovili, da uporaba samoevalvacije vpliva na prepričanja učiteljev, na njihovo zavedanje šibkih in dobrih točk v vedenju ter posledično 
na funkcioniranje šole. $\mathrm{V}$ raziskavi so sicer ugotavljali vpliv na dosežke učencev, ki ni bil pomemben, so pa ugotovili posredne učinke. Učitelji naj bi bili po uporabi samoevalvacijskih inštrumentov bolj usmerjeni v dosežke, poučevanje naj bi bolj prilagajali potrebam učencev, v večji meri pa so se udeleževali tudi strokovnih izobraževanj. Nekateri učitelji so poročali tudi o izboljšanju svojega vedenja v razredu. Avtorji so zaključili, da je uporaba samoevalvacije spremenila nekatere procese $\mathrm{v}$ razredu in šoli, ki bi dolgoročno lahko vplivali tudi na dosežke učencev.

\section{Dosežki učencev}

Različne raziskave so obravnavale dosežke učencev tako $\mathrm{v}$ povezavi $\mathrm{s}$ prepričanji učiteljev, $\mathrm{z}$ vedenjem učiteljev, pa tudi v odnosu do samoevalvacije.

Asthon je leta 1990 (v Fang, 1996) ugotovil, da so se pedagoški delavci pričeli zavedati, da imajo učitelji implicitne teorije o učencih, predmetu, ki ga poučujejo, in njihovi odgovornosti $\mathrm{v}$ zvezi $\mathrm{s}$ poučevanjem in da te implicitne teorije vplivajo na njihov odziv na izobraževanje ter njihovo poučevanje. Prepričanja učiteljev pa vplivajo tudi na njihova pričakovanja do učencev. C. Peklaj in sodelavke (2009) namreč pravijo, da so eden od pomembnih mehanizmov delovanja učiteljev na učence pričakovanja učiteljev v povezavi z določenimi spremenljivkami pri učencih. Učitelji se nagibajo k določenim načinom zaznavanja učencev glede na njihovo šolsko uspešnost ter glede na njihovo vedenje v razredu, kar vpliva na učiteljevo vedenje do določenih učencev (Hattie, 2009).

Creemers in Kyriakides (2008) navajata, da je vedenje učitelja povezano z uspešnostjo učenca, Creemers (1994) pa poleg tega navaja, da je učitelj osrednja komponenta pouka. Tudi nizozemski raziskovalci (Tartwijk, Brekelmans in Wubbels, 1998), pa tudi Hattie (2009) v svoji metaanalitični študiji, ugotavljajo, da lahko učitelji s svojim vedenjem vplivajo na učne dosežke učencev.

Raziskave o vplivu samoevalvacije na dosežke učencev pa si niso enotne o tem, ali učiteljevo vedenje sploh vpliva na učne dosežke učencev in, če ta vpliv obstaja, v kolikšni meri se kaže na učnih dosežkih učencev. Pregled rezultatov raziskav učinkovitosti šol kaže, da so evalvacijske prakse na ravni šole in razreda pozitivno povezane z dosežki učencev (Scheerens in Bosker, 1997, v Scheerens, 2002). Hofman, Dijkstra in Hofman (2009) so šole razdelili glede na štiri tipe samoevalvacije: (1) šole, ki skoraj nimajo samoevalvacije, (2) šole, ki so povprečne $\mathrm{v}$ samoevalvaciji, (3) šole $\mathrm{z}$ napredno samoevalvacijo in (4) šole $z$ »mešano« samoevalvacijo. Ugotovili so, da so šole $\mathrm{z}$ bolj napredno samoevalvacijo (visoki dosežki na lestvicah odgovornosti in izboljšav na šoli) kvalitetnejše glede na izrabo časa za učenje, ki je na voljo, pedagoško in didaktično uspešnost učiteljev, šolsko klimo, usklajevanje $\mathrm{z}$ učnimi potrebami učencev, aktivno in neodvisno vlogo učencev in višjo kvaliteto podpore in usmerjanja učencev. Kljub temu pa v raziskavi niso potrdili, da učenci na šolah $\mathrm{z}$ najbolj napredno samoevalvacijo dosegajo najvišje dosežke. Potrdili pa so, da učenci s šol, ki skoraj ne izvajajo samoevalvacije, dosegajo pomembne nižje dosežke pri matematiki. V raziskavi, ki sta jo izvedla Tymms in Albone (2002, v Hofman idr., 2009; tudi v Schildkamp idr., 2009), se je pokazala nizka, vendar pozitivna povezanost uporabe samoevalvacijskih instrumentov in dosežkov učencev. Samoevalvacijski instrumenti so vključevali vprašalnike za vodje šol, učitelje in učence o dejavnikih na nivoju šole in razreda, ki vplivajo na učinkovitost šole in dosežke učencev (Schildkamp idr., 2009). V že omenjeni raziskavi, ki so jo izvedli Schildkamp in sodelavci, pa niso ugotovili povezav med dosežki učencev in uporabo samoevalvacijskega instrumenta. Demetriou in Kyriakides (2012) pa sta v svoji raziskavi šolam nudila podporo za vzpostavitev samoevalvacije in jih spodbujala, da samoevalvacijo tudi izvajajo. Šole sta razdelila na tri skupine: prvi skupini je bila zagotovljena le podpora za izvedbo samoevalvacije (tj. obravnava X1), procesi za oblikovanje odločitev o oblikah aktivnosti in akcijskih načrtov pa so bili prepuščeni šolam; drugi skupini so poleg podpore nudili predstavitev dinamičnega modela učinkovitosti izobraževanja, ki združuje ugotovitve različnih raziskav o učinkovitosti izobraževanja (obravnava X1 in X2); v tretji skupini pa je poleg obravnav $\mathrm{X} 1$ in X2 bila zagotovljena tudi podpora pri vzpostavljanju varnega in odprtega vzdušja (obravnava X3) pred uvedbo kakršnihkoli sprememb. $\mathrm{Na}$ začetku in koncu šolskega leta so izmerili dosežke učencev. Ugotovili so, da so učenci $\mathrm{v}$ vseh treh eksperimentalnih skupinah dosegli višje dosežke kot učenci v kontrolni skupini. Velikost učinka vsakega od pristopov samoevalvacije je bila sicer relativno majhna, kar pa je tudi v skladu $\mathrm{z}$ rezultati drugih raziskav, ki pravijo, da je v začetni fazi intervencij učinek na dosežek učencev majhen (Demetriou in Kyriakides, 2012; Slavin, Lake in Groff, 2009).

$\mathrm{Na}$ podlagi ugotovitev omenjenih raziskav o vplivu samoevalvacije na dosežke učencev, pa tudi povezav med samoevalvacijo $\mathrm{v}$ šoli, prepričanji in vedenjem učiteljev, smo v naši raziskavi želeli ugotoviti, ali lahko različni načini spodbujanja samoevalvacije vplivajo na spreminjanje prepričanj učiteljev o samoevalvaciji, pa tudi na njihovo vedenje v razredu ter na dosežke učencev. Da bi prišli do teh ugotovitev, smo, podobno kot Demetriou in Kyriakides (2012), šole razdelili v skupine z različnimi aktivnostmi spodbujanja samoevalvacije.

Na podlagi zasnove raziskave smo pričakovali, da se bodo prepričanja učiteljev o samoevalvaciji pomembno spremenila $\mathrm{v}$ drugi in tretji skupini šol, v katerih smo spodbujali samoevalvacijo, v kontrolni skupini šol pa ne bo razlik. Večje razlike $\mathrm{v}$ spremembi prepričanj učiteljev smo pričakovali $\mathrm{v}$ tretji skupini, kjer smo samoevalvacijo spodbujali v bolj intenzivni obliki. Poleg tega smo pričakovali, da se bo v drugi in tretji skupini pokazala težnja k spremembi vedenja učiteljev v razredu, o katerem bodo poročali učitelji sami. Pričakovali smo, da bodo tudi učenci zaznali spremembo vedenja učiteljev $\mathrm{v}$ eksperimentalnih skupinah, predvsem v tretji skupini. Želeli pa smo tudi preveriti, ali imajo različne aktivnosti v šolah vpliv na dosežke učencev. 


\section{Metoda}

\section{Vzorec}

V raziskavi je sodelovalo 111 učiteljev 4. razreda iz 59 slovenskih osnovnih šol. Šole so bile naključno izbrane, pri čemer smo kontrolirali regijsko pripadnost in velikost šole. Na večini šol so se $\mathrm{v}$ raziskavo vključili vsi oddelki 4. razreda, vendar ne na vseh šolah. Izmed 111 sodelujočih učiteljev 4. razreda je bilo 110 učiteljic in le en učitelj, kar je realno razmerje spolne strukture učiteljev v nižjih razredih slovenskih osnovnih šol. Povprečna starost učiteljev je bila 44,7 let, povprečno število let poučevanja pa 22,5 let (v razponu od dveh do 37 let).

Poleg učiteljev so $\mathrm{v}$ raziskavi sodelovali tudi njihovi učenci (za katere smo pridobili soglasja s strani staršev). Vseh sodelujočih učencev je bilo 2153 , od tega $50,7 \%$ učencev in $49,3 \%$ učenk.

\section{Pripomočki}

\section{Stališča do samoevalvacije}

Za ugotavljanje stališč do samoevalvacije $\mathrm{v}$ šoli smo prilagodili vprašalnik Stališča do samoevalvacije (Attitudes towards self-evaluation) avtorjev Vanhoof in sodelavci (2009). Vprašalnik je namenjen ugotavljanju stališč učiteljev in ravnateljev o samoevalvaciji v šoli. Izvornemu vprašalniku, ki vključuje 12 postavk, smo dodali štiri postavke. Postavke so bile postavljene v obliki nasprotujočih se trditev. Učitelj je na 6-stopenjski lestvici označil, s katero od nasprotujočih trditev se bolj strinja. Učitelj, ki je označil v smeri 1, je tako sporočil, da se bolj strinja s trditvijo na levi (npr. Samoevalvacija nam ne pove nič novega.); učitelj, ki je označil v smeri 6, pa je sporočil, da se bolj strinja s trditvijo na desni (npr. Samoevalvacija nas lahko marsikaj nauči.). Postavke tvorijo eno lestvico - Stališča do samoevalvacije. Vprašalnik so učitelji izpolnjevali trikrat - na začetku šolskega leta, na koncu šolskega leta in po preteku šestih mesecev. Vanhoof in sodelavci v svoji raziskavi poročajo o dobri notranji konsistentnosti lestvice (Cronbachova $\alpha=0,92$ ).

$\mathrm{Na}$ našem vzorcu smo s pomočjo analize glavnih komponent ugotovili, da ima lestvica $\mathrm{z}$ dodanimi postavkami prav tako koherentno enokomponentno strukturo. Cronbachovi alfa koeficienti so se izkazali kot ustrezni $-\mathrm{v}$ prvem merjenju je bil $\alpha=0,86, \mathrm{v}$ drugem $\alpha=$ 0,85 , v tretjem pa $\alpha=0,86$.

\section{Vprašalnik o vedenju v razredu}

Za merjenje vedenja učiteljev v razredu smo prilagodili Vprašalnik o vodenju pouka, ki je bil razvit v namen raziskave o kompetencah učiteljev (Kalin, Valenčič Zuljan, Peklaj, Puklek Levpušček in Pečjak, 2007). Sestavlja ga 5 lestvic (skupaj 43 trditev): Didaktično metodični vidik (primer postavke: Preverjam, kako so učenci naredili domačo nalogo.), Vodenje oddelka (primer postavke: Če se učenci neprimerno vedejo, jih opozorim.), Preverjanje in ocenjevanje (primer postavke: Nekaj dni pred testom naredimo podobne naloge kot bodo v testu.), Spodbujanje celostnega razvoja učencev (primer postavke: Učence spodbujam, da upoštevajo mnenje drugih.), Uporaba IKT-ja (primer postavke: Učence spodbujam, da iščejo informacije tudi po internetu.). V raziskavi C. Peklaj in sodelavk (2009) so ocenjene Cronbachove alfe za vse lestvice znašale več kot 0,80 . Vprašalnik je $\mathrm{v}$ osnovi namenjen učencem, zato smo ga za učitelje prilagodili, pri čemer smo vključili le 35 trditev ter ga poimenovali Vprašalnik o vedenju v razredu. Učitelji so na vsako od trditev odgovarjali tako, da so na štiristopenjski lestvici označili, kako pogosto se $\mathrm{v}$ razredu vedejo na določen način (1 - nikoli, 2 - včasih, 3 - pogosto, 4 - vedno). Vprašalnik so učitelji izpolnjevali trikrat.

Ker nekaterih postavk nismo vključili, je bila struktura posameznih lestvic manj stabilna. Kljub temu smo obdržali izvorne lestvice, analiza glavnih komponent pa je pokazala zadovoljive rezultate tudi $\mathrm{v}$ okviru enotne lestvice, zato smo uporabili tudi rezultat enotne lestvice - Vedenje $v$ razredu. V našem vzorcu so zanesljivosti enotne lestvice Vedenje $v$ razredu pri vseh treh merjenjih nad 0,80 , zanesljivosti ostalih lestvic pa so $\mathrm{v}$ razponu od 0,46 pri lestvici Preverjanje in ocenjevanje, kar je sicer zelo nizka zanesljivost, do 0,80 pri lestvici Spodbujanje celostnega razvoja učencev.

\section{Vprašalnik o pouku}

Informacije o vedenju učitelja $v$ razredu smo pridobili tudi s pomočjo vprašalnika za učence, $v$ katerem smo jih spraševali o vedenju njihovega učitelja $v$ razredu. Da bi bili podatki primerljivi s samoocenjevanjem učiteljev, smo uporabili iste postavke Vprašalnika o vodenju pouka (Kalin in dr., 2007) kot pri učiteljih. Prilagojeni Vprašalnik o pouku smo uporabili dvakrat, in sicer pri prvem merjenju ob začetku šolskega leta ter pri drugem merjenju ob koncu šolskega leta. Učenci so na vsako od trditev odgovorili tako, da so na štiristopenjski lestvici označili, kako pogosto se določeno vedenje pojavlja pri njihovi učiteljici/učitelju. Tako kot pri učiteljih smo uporabili lestvico Vedenje učitelja $v$ razredu (Cronbachov alfa koeficient zanesljivosti je 0,90 pri prvem merjenju oz. 0,89 pri drugem merjenju) ter lestvice Didaktično metodični vidik $(\alpha=0,75$ oz. 0,70$)$, Vodenje oddelka ( $\alpha$ $=0,79$ oz. $\alpha=0,74)$, Preverjanje in ocenjevanje $(\alpha=0,67$ oz. $\alpha=0,66)$, Spodbujanje celostnega razvoja učencev ( $\alpha$ $=0,77$ oz. $\alpha=0,78)$ ter Uporaba IKT-ja $(\alpha=0,63$ oz. $\alpha=$ $0,60)$.

\section{Znanje učencev}

Znanje učencev smo preverjali s pomočjo izbranih nalog iz mednarodne raziskave TIMSS 2007, kije pokrivala področje matematike in naravoslovja (Japelj Pavešić, Svetlik in Čuček, 2008). Uporabili smo štiri različne 
delovne zvezke, ki so bili naključno, vendar številčno enakomerno porazdeljeni po razredih. Vsak učenec je rešil dva delovna zvezka, enega na začetku, drugega pa na koncu šolskega leta. Dosežki učencev so izraženi s pomočjo WLE (ang. wighted likelihood estimates) (Warm, 1989), saj nam ta način omogoča primerjavo dosežkov na različnih delovnih zvezkih oz. nalogah. Poleg dosežkov učencev pri matematiki in naravoslovju v posameznem delu šolskega leta smo izračunali tudi napredek učencev, in sicer tako, da smo na primerljivi lestvici dosežek učenca ob začetku šolskega leta odšteli od dosežka učenca ob koncu šolskega leta.

\section{Postopek}

Raziskava je bila zasnovana kot eksperiment s tremi skupinami šol in dvema ločenima preverjanjema, vključeno pa je bilo tudi preverjanje trajnosti sprememb po nekajmesečnem preteku programa. Sodelujoče šole smo po slučaju razdelili v tri skupine. Prva skupina je bila kontrolna; šole $\mathrm{v}$ tej skupini niso bile deležne dodatnih aktivnosti med šolskim letom. Ostali dve skupini (druga in tretja) sta bili eksperimentalni skupini.

Pred izvedbo raziskave smo pridobili soglasja učiteljev in učencev. Raziskavo smo nato izvedli v treh ločenih obdobjih. Prvi del je bil izveden na začetku šolskega leta 2010/2011, ko smo izvedli preverjanje znanja iz matematike in naravoslovja pri učencih, reševali pa so tudi vprašalnik o vedenju učitelja $\mathrm{v}$ razredu (Vprašalnik o pouku). Od učencev smo pridobili tudi nekaj demografskih podatkov. Ta del raziskave so izvedli usposobljeni izvajalci. Izvedba je potekala v prvih treh šolskih urah na dogovorjeni dan. $\mathrm{V}$ času izvedbe prvega dela raziskave $\mathrm{z}$ učenci so učitelji 4. razredov odgovorili na vprašanja o prepričanjih o samoevalvaciji(Stališčadosamoevalvacije)ternavprašanja o lastnem vedenju (Vprašalnik o vedenju v razredu). Od učiteljev smo pridobili tudi nekaj demografskih podatkov. Po izvedbi prvega dela raziskave smo izvedli ločeni srečanji s skupinama 2 in 3 . Tekom šolskega leta so nato $\mathrm{v}$ šolah potekale različne aktivnosti glede na skupino, $\mathrm{v}$ kateri je bila šola. V obeh eksperimentalnih skupinah smo šole spodbujali, da so se usmerile na specifično področje dosežkov, učitelje pa, da so izvedli samoevalvacijo na tem področju. Eksperimentalni skupini sta se ločevali glede na intenzivnost spodbujanja samoevalvacije. V skupini 2 smo izvedli eno skupno srečanje, na katerem smo jim predstavili pomen samoevalvacije in jih spodbudili, da $\mathrm{v}$ svojem razredu in na šoli izvajajo samoevalvacijo glede na predstavljeni model korakov samoevalvacije (Brejc in Zavašnik Arčnik, 2010; Musek Lešnik in Bergant, 2001; Poljanšek in Bucik, 2002), ki je v Sloveniji en izmed običajnih pristopov $\mathrm{k}$ samoevalvaciji. Skupino smo tudi poučili o pripravi akcijskega načrta, ki so ga pripravili po skupnem srečanju na šoli ter pisanju poročila o izvedbi samoevalvacije, ki so nam ga oddali ob koncu šolskega leta. Tekom leta smo jih spremljali preko elektronske pošte in telefonskih pogovorov, pri katerih smo jih predvsem spodbujali, da so nam ob dogovorjenem času poslali akcijske načrte in poročila, odgovarjali pa smo tudi na njihova vprašanja o načinih izvedbe samoevalvacije. Pogostost komunikacije je bila odvisna od intenzivnosti aktivnosti posamezne šole. V skupini 3 smo izvedli podobno skupno srečanje, na katerem so učitelji dobili informacije o samoevalvaciji, o akcijskem načrtu in poročilu o samoevalvaciji. Ko so na šolah pripravili akcijski načrt, smo jih obiskali in ga skupaj z njimi pregledali, vključili pa smo tudi ostale učitelje na šoli. Nato smo njihovo delo sprotno spremljali in jim pomagali pri izvedbi akcijskega načrta (komunikacija preko elektronske pošte in telefonski pogovori z odzivi na njihovo delo, o katerem so nam poročali, ter vmesni vprašalnik o poteku samoevalvacije na šoli). Pogostost komunikacije je bila prav tako odvisna od intenzivnosti aktivnosti posamezne šole. Učitelje na šolah smo tudi spodbujali, da sodelujejo med seboj. Ob koncu šolskega leta smo od njih pridobili poročilo o samoevalvaciji.

Drugi del raziskave je potekal ob koncu šolskega leta 2010/2011. Usposobljeni izvajalci so izvedli drugi del preverjanja znanja o matematiki in naravoslovju z učenci, pa tudi vprašalnik o vedenju učitelja v razredu. Učitelji so $\mathrm{v}$ tem času ponovno izpolnili vprašalnik Stališča do samoevalvacije ter Vprašalnik o vedenju v razredu.

V jeseni 2011 smo učitelje ponovno prosili, da nam odgovorijo na vprašanja. Tako so zopet izpolnili vprašalnik Stališča do samoevalvacije ter Vprašalnik o vedenju v razredu. S tem smo želeli preveriti trajnost sprememb po preteku programa.

\section{Rezultati}

Rezultate smo razdelili na tri dele. V prvem delu so predstavljeni rezultati prepričanj o samoevalvaciji, $\mathrm{v}$ drugem delu rezultati o vedenju učitelja (tako z vidika učitelja kot $\mathrm{z}$ vidika učencev), v tretjem delu pa rezultati o znanju učencev. Analiza rezultatov je izvedena s pomočjo dvosmerne analize variance za mešane načrte.

\section{Prepričanja o samoevalvaciji}

V tabeli 1 so prikazani glavni učinek skupine šole, v katerih so bili učitelji, glavni učinek časa merjenja ter interakcija med pripadnostjo skupini in merjenji na dosežke na lestvici Stališča do samoevalvacije.

Rezultati dvosmerne analize variance za mešane načrte v tabeli 1 kažejo, da tako glavni učinek časa merjenja kot tudi glavni učinek skupine nista statistično pomembna. $\mathrm{V}$ vseh treh merjenjih so torej učitelji, če ne upoštevamo skupin, dosegli podobna povprečja na lestvici Stališča do samoevalvacije. Tudi skupine šol same po sebi nimajo učinka na dosežek na lestvici Stališča do samoevalvacije. Poleg tega je tudi interakcija med pripadnostjo skupini in merjenji stališč statistično nepomembna. Tudi velikosti vseh učinkov so zanemarljive; pojasnijo namreč le od 1 do $5 \%$ variance. 
Tabela 1. Povzetek analize variance za dosežke na lestvici Stališča do samoevalvacije

\begin{tabular}{lrrrrrr}
\hline Vir variabilnosti & $S S$ & $d f$ & $M S$ & $F$ & $p$ & parcialna $\eta^{2}$ \\
\hline Med skupinami & & & & & & 0,05 \\
$\quad$ skupina & 0,93 & 2 & 0,47 & 2,20 & 0,117 & \\
$\quad$ napaka & 18,79 & 89 & 0,21 & & & \\
Znotraj skupin & & & & & & 0,03 \\
$\quad$ merjenje & 0,90 & 2 & 0,45 & 2,63 & 0,075 & 0,01 \\
$\quad$ merjenje x skupina & 0,33 & 4 & 0,08 & 0,49 & 0,745 & \\
$\quad$ napaka (merjenje) & 30,42 & 178 & 0,17 & & & \\
\hline
\end{tabular}

Tabela 2. Povzetek analize variance za dosežke na lestvici Vedenje v razredu

\begin{tabular}{lrrrrrr}
\hline Vir variabilnosti & $S S$ & $d f$ & $M S$ & $F$ & $p$ & parcialna $\eta^{2}$ \\
\hline Med skupinami & & & & & & \\
$\quad$ skupina & 0,16 & 2 & 0,08 & 2,77 & 0,068 & 0,06 \\
$\quad$ napaka & 2,73 & 95 & 0,03 & & & \\
Znotraj skupin & & & & & & 0,03 \\
$\quad$ merjenje & 0,13 & 2 & 0,06 & 2,98 & 0,053 & 0,01 \\
$\quad$ merjenje x skupina & 0,05 & 4 & 0,01 & 0,60 & 0,660 & \\
$\quad$ napaka (merjenje) & 4,02 & 190 & 0,02 & & & \\
\hline
\end{tabular}

\section{Vedenje učiteljev}

Podatke o vedenju učiteljev smo pridobili tako s strani učiteljev kot s strani njihovih učencev.

$\mathrm{V}$ tabeli 2 je prikazan povzetek dvosmerne analize variance za mešane načrte Vprašalnika o vedenju v razredu, ki so ga izpolnjevali učitelji, in sicer za dosežke na skupni lestvici Vedenje v razredu.

Rezultati analize variance v tabeli 2 kažejo, da tako glavni učinek časa merjenja kot glavni učinek skupine nimata statistično pomembnega učinka na dosežke na lestvici Vedenje v razredu. V vseh treh merjenjih in v vseh treh skupinah so torej učitelji dosegli podobna povprečja na lestvici Vedenje $\mathrm{v}$ razredu. Tudi interakcija med

Tabela 3. Aritmetične sredine in standardni odkloni po posameznih skupinah in merjenjih na lestvici Vedenje $v$ razredu.

\begin{tabular}{lccr}
\hline & $N$ & $M$ & $S D$ \\
\hline merjenje 1 & 98 & 3,44 & 0,19 \\
skupina 1 & 39 & 3,43 & 0,23 \\
skupina 2 & 29 & 3,48 & 0,16 \\
skupina 3 & 30 & 3,43 & 0,16 \\
& & & \\
\hline merjenje 2 & 98 & 3,48 & 0,23 \\
skupina 1 & 39 & 3,46 & 0,26 \\
skupina 2 & 29 & 3,55 & 0,23 \\
skupina 3 & 30 & 3,43 & 0,18 \\
& & & \\
\hline merjenje 3 & 98 & 3,43 & 0,20 \\
skupina 1 & 39 & 3,41 & 0,23 \\
skupina 2 & 29 & 3,51 & 0,17 \\
skupina 3 & 30 & 3,38 & 0,18 \\
\hline
\end{tabular}

merjenji ter pripadnostjo skupini ni statistično pomembna. Velikosti učinkov so majhni tako pri interakciji kot pri obeh glavnih učinkih.

Pregled opisnih statistik v tabeli 3 nam sicer kaže, da pri prvem merjenju med učitelji ni bilo velikih razlik $\mathrm{v}$ povprečjih na lestvici Vedenje $\mathrm{v}$ razredu, pri drugem merjenju pa so se razlike povečale. Hkrati vidimo, da so pri drugem merjenju učitelji poročali, da se je njihovo vedenje izboljšalo. Pri tretjem merjenju pa so v vseh treh skupinah povprečja zopet nižja $\mathrm{v}$ primerjavi z drugim merjenjem. Poleg tega lahko vidimo, da najvišja poprečja na lestvici Vedenje v razredu dosegajo učitelji v drugi skupini in sicer pri vseh treh merjenjih.

Razlike med skupinami in merjenji smo pogledali tudi na nivoju ostalih lestvic vprašalnika. Na lestvici Didaktično metodični vidik je pomemben učinek merjenja $\left(F(2,202)=3,95, p=0,021, \eta_{\text {partial }}^{2}=0,04\right)$, ni pa pomembnega učinka skupine in interakcije. Pri drugem merjenju so učitelji poročali o najbolj pozitivnem vedenju $(M=3,25 ; S D=0,25)$, prvo $(M=3,19 ; S D=0,23)$ in tretje merjenje $(M=3,20 ; S D=0,24)$ pa sta bili primerljivi. Na lestvicah Vodenje oddelka, Spodbujanje celostnega razvoja učencev ter Preverjanje in ocenjevanje ni pomembnih učinkov merjenja in skupin, niti ni učinka interakcije. Na lestvici Uporaba IKT-ja je prav tako pomemben učinek merjenja $\left(F(2,208)=3,65, p=0,032, \eta_{\text {partial }}^{2}=0,03\right)$, ne pa tudi skupine in interakcije. Podobno kot na lestvici Didaktično metodični vidik so učitelji poročali o najbolj pozitivnem vedenju pri drugem merjenju $(M=3,08$; $S D=0,54)$, povprečji pri prvem $(M=2,98 ; S D=0,52)$ in tretjem merjenju $(M=2,95 ; S D=0,52)$ pa sta bili primerljivi. Pri drugem merjenju so torej učitelji poročali o bolj pozitivnem vedenju na dveh lestvicah - Didaktično metodični vidik in Uporaba IKT. 
Tabela 4. Povzetek analize variance za dosežke na lestvici Vedenje učitelja v razredu iz Vprašalnika o pouku

\begin{tabular}{lrrrrrr}
\hline Vir variabilnosti & $S S$ & $d f$ & $M S$ & $F$ & $p$ & parcialna $\eta^{2}$ \\
\hline Med skupinami & & & & & & \\
$\quad$ skupina & 1,72 & 2 & 0,86 & 8,38 & 0,000 & 0,01 \\
$\quad$ napaka & 121,65 & 1183 & 0,10 & & & \\
Znotraj skupin & & & & & & \\
$\quad$ merjenje & 14,10 & 1 & 14,10 & 128,47 & 0,000 & 0,10 \\
$\quad$ merjenje x skupina & 0,69 & 2 & 0,35 & 3,16 & 0,043 & 0,01 \\
$\quad$ napaka (merjenje) & 129,87 & 1183 & 0,11 & & & \\
\hline
\end{tabular}

$\mathrm{V}$ tabeli 4 so prikazani rezultati analize variance za dosežke na lestvici Vedenje učitelja v razredu iz Vprašalnika o pouku, ki so ga izpolnjevali učenci.

Rezultati analize variance v tabeli 4 nam kažejo, da sta tako učinek merjenja kot učinek skupine statistično pomembna, prav tako tudi interakcija. Učenci so pri prvem merjenju $(M=3,23 ; S D=0,40)$ pomembno bolj pozitivno ocenjevali vedenje svojih učiteljev kot pri drugem merjenju $(M=3,08 ; S D=0,40)$. Pomembne pa so tudi razlike med skupinami. Iz učinka interakcije ter slike 1 vidimo, da merjenje in skupina sovplivata na dosežke, čeprav je velikost učinka zanemarljiva. Na sliki 1 vidimo, da so razlike med skupinami pri prvem merjenju večje kot pri drugem merjenju. Razlika med tretjo in kontrolno skupino je pri drugem merjenju praktično izginila. V vseh skupinah se je torej povprečni dosežek v drugem merjenju v primerjavi s prvim znižal, vendar je bilo to znižanje najbolj izrazito v primeru tretje skupine. Druga skupina ima pri obeh merjenjih najvišje povprečje.

Razlike med skupinami in merjenji smo raziskali tudi na ostalih lestvicah. Na lestvici Didaktično metodični vidik so pomembni tako učinek merjenja $(F(1,1523)=99,84, p$ $\left.=0,000, \eta_{\text {partial }}^{2}=0,06\right)$, skupine $(F(2,1523)=16,11, p=$ $\left.0,000, \eta_{\text {partial }}^{2}=0,02\right)$ kot tudi interakcije $(F(2,1523)=5,98$, $\left.p=0,003, \eta_{\text {partial }}^{2}=0,01\right) . \mathrm{V}$ vseh treh skupinah se je pri drugem merjenju povprečni dosežek na lestvici Didaktično metodični vidik v primerjavi s prvim znižal, pri čemer je bilo to znižanje, podobno kot pri enotni lestvici Vedenje

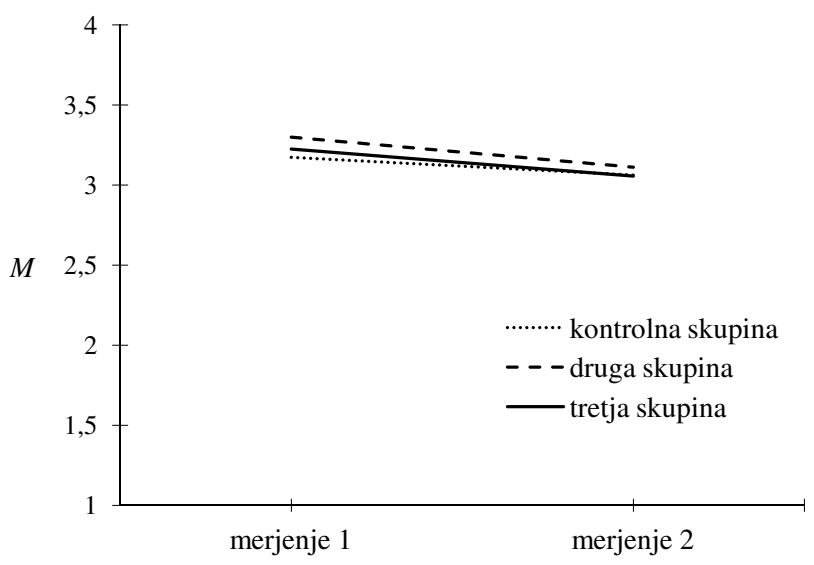

Slika 1. Dvosmerna interakcija med merjenji in skupinami šol na lestvici Vedenje učitelja v razredu. učitelja v razredu, najbolj izrazito v tretji skupini, najmanj pa $\mathrm{v}$ prvi. Učenci v drugi skupini so na obeh merjenjih najbolj pozitivno ocenjevali vedenje svojih učiteljev. Pri ostalih lestvicah učinek interakcije ni bil pomemben. Na lestvicah Vodenje oddelka $(F(1,1681)=112,67, p=$ $\left.0,000, \eta_{\text {partial }}^{2}=0,06\right)$ ter Preverjanje in ocenjevanje $(F(1$, $\left.1828)=88,85, p=0,000, \eta_{\text {partial }}^{2}=0,05\right)$ je pomemben le učinek merjenja. Na omenjenih dveh lestvicah so učenci pri drugem merjenju v vseh treh skupinah manj pozitivno ocenjevali vedenje svojih učiteljev kot pri prvem merjenju. $\mathrm{Na}$ lestvici Spodbujanje celostnega razvoja učencev pa je bil poleg učinka merjenja $(F(1,1711)=222,30, p=0,000$, $\left.\eta_{\text {partial }}^{2}=0,12\right)$ pomemben tudi učinek skupine $(F(2,1711)=$ $\left.3,06, p=0,047, \eta_{\text {partial }}^{2}=0,01\right)$. Učenci so tudi na tej lestvici pri drugem merjenju manj pozitivno ocenjevali vedenje svojih učiteljev kot pri prvem merjenju, razlike pa so bile tudi med skupinami. Učenci v drugi skupini so najbolj pozitivno ocenjevali vedenje svojih učiteljev. Pri lestvici Uporaba IKT-ja pa je pomemben le učinek skupine $(F(2$, $\left.1786)=18,96, p=0,000, \eta_{\text {partial }}^{2}=0,02\right)$. Učenci so torej $\mathrm{v}$ različnih skupinah različno ocenjevali vedenje svojih učiteljev - najbolj pozitivno v drugi skupini, najmanj pa v kontrolni.

\section{Znanje učencev}

Zanimalo nas je tudi znanje učencev v treh skupinah šol. Dosežke učencev smo primerjali na področju matematike in naravoslovja.

Najprej nas je zanimalo, ali so učenci tekom šolskega leta pridobili pomembno količino znanja. Analiza variance (glej tabelo 5) nam kaže, da je učinek merjenja statistično pomemben tako pri matematiki kot pri naravoslovju. Pri obeh predmetih so višja povprečja dosežkov pri drugem merjenju (matematika: merjenje $1(M=100,08$; $S D=$ $39,86)$, merjenje $2(M=121,25 ; S D=31,51)$; naravoslovje: merjenje $1(M=100,07 ; S D=30,00)$, merjenje $2(M=$ $118,09 ; S D=30,38)$, kar pomeni, da so v enem šolskem letu učenci pridobili pomembno veliko znanja, hkrati pa s tem pokažemo tudi veljavnost našega testa. Dvig povprečij je podoben pri vseh skupinah.

Učinek skupine tako pri matematiki kot pri naravoslovju ni statistično pomemben, prav tako tudi ne učinek interakcije. Uvrstitev šol v skupine $\mathrm{z}$ različnimi aktivnostmi torej ni vplivalo na dosežke učencev. 
Tabela 5. Povzetek analize variance za dosežke pri matematiki in naravoslovju

\begin{tabular}{|c|c|c|c|c|c|c|}
\hline Vir variabilnosti & $S S$ & $d f$ & $M S$ & $F$ & $p$ & parcialna $\eta^{2}$ \\
\hline \multicolumn{7}{|l|}{ Matematika } \\
\hline \multicolumn{7}{|l|}{ Med skupinami } \\
\hline skupina & 1703,32 & 2 & 815,66 & 1,07 & 0,343 & 0,00 \\
\hline napaka & 1546070,17 & 1943 & 795,71 & & & \\
\hline \multicolumn{7}{|l|}{ Znotraj skupin } \\
\hline merjenje & 431887,01 & 1 & 431887,01 & 1471,14 & 0,000 & 0,43 \\
\hline merjenje $\mathrm{x}$ skupina & 5,33 & 2 & 2,67 & 0,01 & 0,991 & 0,00 \\
\hline napaka (merjenje) & 570412,15 & 1943 & 293,57 & & & \\
\hline \multicolumn{7}{|l|}{ Naravoslovje } \\
\hline \multicolumn{7}{|l|}{ Med skupinami } \\
\hline skupina & 585,31 & 2 & 292,65 & 0,41 & 0,665 & 0,00 \\
\hline napaka & 1397544,48 & 1952 & 715,95 & & & \\
\hline \multicolumn{7}{|l|}{ Znotraj skupin } \\
\hline merjenje & 314710,45 & 1 & 314710,45 & 1142,41 & 0,000 & 0,37 \\
\hline merjenje $\mathrm{x}$ skupina & 1347,47 & 2 & 673,73 & 2,45 & 0,087 & 0,00 \\
\hline napaka (merjenje) & 537736,67 & 1952 & 275,48 & & & \\
\hline
\end{tabular}

Zanimalo nas je tudi, ali obstajajo razlike med skupinami v napredku učencev pri posameznem predmetu. Rezultati primerjav nam kažejo, da razlike med skupinami tako pri matematiki kot pri naravoslovju niso pomembne.

\section{Razprava}

V raziskavi smo želeli ugotoviti, ali spodbujanje procesa samoevalvacije vpliva na spremembo prepričanj učiteljev do tega procesa. Ker je spreminjanje prepričanj izhodišče za spremembo vedenja učitelja v razredu, le-to pa naj bi vplivalo tudi na dosežke učencev (Tartwijk idr., 1998), nas je zanimalo, ali se bodo spremembe pokazale tudi na teh dveh področjih. Ker so prepričanja relativno stabilna, posledično pa tudi vedenje in dosežki, velikih učinkov nismo pričakovali; tudi zato, ker je raziskava potekala le eno šolsko leto.

$\mathrm{Na}$ podlagi rezultatov na lestvici Stališča do samoevalvacije lahko ugotovimo, da rezultati niso v skladu s hipotezo, ki je predvidevala, da se bodo prepričanja o samoevalvaciji pomembno spremenila $v$ drugi in tretji skupini. V vseh treh merjenjih in $\mathrm{v}$ vseh treh skupinah so bila namreč povprečja na lestvici stališč primerljiva. Tudi interakcijski učinki niso bili statistično pomembni. Ugotovimo lahko torej, da so prepričanja precej stabilna, saj potrebujemo za spremembo veliko časa. Ena izmed omejitev raziskave, kratko časovno obdobje izvedbe, je lahko tudi razlog, da ni prišlo do pomembnih sprememb v prepričanjih.

Čeprav razlike med skupinami glede na prepričanja o samoevalvaciji niso pomembne, nas je zanimalo, ali so med skupinami učiteljev pomembne razlike v vedenju. To smo ugotavljali tako $\mathrm{z}$ vidika samoocenjevanja učiteljev kot $\mathrm{z}$ vidika učencev. Tako kot pri rezultatih na lestvici Stališča do samoevalvacije tudi na enotni lestvici Vedenje v razredu ugotavljamo, da so učitelji v vseh treh skupinah in pri vseh merjenjih poročali o primerljivem vedenju $\mathrm{v}$ razredu. $\mathrm{Na}$ podlagi rezultatov opisnih statistik lahko ugotovimo, da na začetku ni bilo razlik v vedenju učiteljev med skupinami šol, kar je skladno s pričakovanji. Pri drugem merjenju pa so učitelji v vseh skupinah poročali, da se je njihovo vedenje $v$ razredu izboljšalo, vendar razlike med skupinami niso bile pomembne, kar pa ni skladno s hipotezo, pri kateri smo pričakovali, da se bo vedenje najbolj izboljšalo v tretji skupini. So pa pomembni učinki merjenja na dveh podlestvicah in sicer Didaktično metodični vidik ter Uporaba IKT. Učitelji so poročali, da so pri drugem merjenju izboljšali svoje vedenje na teh dveh področjih. Ker pa se je to zgodilo v vseh treh skupinah, ne moremo govoriti o vplivu samoevalvacije na spremembo vedenja učiteljev. Kljub statistični nepomembnosti je bil najvišji dvig povprečja tako pri enotni lestvici kot pri ostalih lestvicah v drugi skupini. Možen razlog je dejstvo, da so imeli v drugi skupini več svobode pri izbiranju aktivnosti, kar običajno pozitivno deluje na vedenje. Zanimivo je, da so učitelji v vseh treh skupinah poročali o manj pozitivnem vedenju v razredu pri zadnjem merjenju, kar kaže na nek zunanji učinek, na primer prenasičenost učiteljev ali pa poučevanje novih učencev in s tem pojavljanje drugačnega vedenja.

Na podlagi podatkov, pridobljenih s strani učencev, pa smo ugotovili, da na ravni enotne lestvice Vedenje učitelja $\mathrm{v}$ razredu obstajajo pomembne razlike tako med obema merjenjema kot med skupinami, pomembno pa je tudi sovplivanje med merjenjem in skupinami na ocenjevanje vedenja učiteljev s strani učencev. Podobno smo ugotovili tudi na lestvici Didaktično metodični vidik. Učenci so svoje učitelje pri drugem merjenju ocenjevali manj pozitivno kot pri prvem, kar smo ugotovili tudi na vseh ostalih lestvicah, razen pri lestvici Uporaba IKT. Razlog je lahko v izkušnjah. Na začetku šolskega leta učenci svojih učiteljev še niso dobro poznali in so morebiti o 
kakšnem vedenju le ugibali, na koncu leta pa so imeli že več izkušenj, na podlagi katerih so lahko (bolje) ocenili vedenje svojih učiteljev. Tako pri prvem kot pri drugem merjenju so najbolj pozitivno ocenjevali svoje učitelje učenci v drugi skupini. Ker so razlike med skupinami pomembne, ne moremo govoriti o enakosti skupin (pri učiteljih so te razlike nepomembne). Ker so torej pri obeh merjenjih vedenje svojih učiteljev najbolj pozitivno ocenjevali učenci $\mathrm{v}$ drugi skupini, $\mathrm{z}$ vidika učencev ne moremo govoriti o učinku samoevalvacije na vedenje učiteljev v razredu.

Pri razlikah med skupinami na nivoju dosežkov učencev nas je predvsem zanimalo, ali obstaja kakšen vpliv aktivnosti samoevalvacije na šoli na te dosežke. Glede na predhodne raziskave smo namreč pričakovali, da tega vpliva ne bo oziroma bo zelo majhen (Demetriou in Kyriakides, 2012; Schildkamp idr., 2009). Na podlagi rezultatov lahko ugotovimo, da skupine $\mathrm{z}$ različnimi aktivnostmi niso vplivale na dosežke učencev pri matematiki in naravoslovju, kar je tudi v skladu z našimi pričakovanji in predhodnimi raziskavami (Demetriou in Kyriakides, 2012; Schildkamp idr., 2009). Prav tako je tudi pri napredku učencev. Je pa spodbuden rezultat, da je razlika med znanjem na začetku in na koncu 4. razreda visoka in pomembna, kar pomeni, da so se učenci v enem šolskem letu veliko naučili, hkrati pa lahko potrdimo primernost uporabljenega testa znanja.

Omenimo lahko tudi nekaj omejitev raziskave. Prva omejitev je časovno obdobje raziskave. Rezultati bi bili verjetno drugačni, če bi raziskava potekala $\mathrm{V}$ večjem časovnem zamiku, saj so za dejansko izvedbo samoevalvacije na šoli in v razredu učitelji imeli na voljo le nekaj mesecev. Druga omejitev je precejšnja »svoboda« učiteljev o načinu izvedbe samoevalvacije, zaradi katere so k izvedbi pristopali z različno intenzivnostjo. Poleg tega šole oziroma učitelji niso bili enako motivirani. V večini sorodnih raziskav se šole za sodelovanje odločijo povsem prostovoljno, $v$ našem primeru pa so bile šole izbrane vnaprej in bile s tem nekako prisiljene v sodelovanje. Imele so sicer možnost zavrnitve, vendar je gotovo sodelovala tudi kakšna, ki se sicer ne bi prostovoljno odločila za sodelovanje, kar vsekakor vpliva na motivacijo. To je seveda lahko tudi prednost raziskave pred drugimi, saj je šlo v naši raziskavi za simulacijo relativno avtentične situacije, kakršna se pojavlja ob uvajanju različnih sistemskih novosti v šole. Samoevalvacija naj bi se namreč izvajala na vsaki šoli, vendar pa so na izvedbeni ravni velike razlike. Ena izmed pomanjkljivosti je tudi ta, da v analizo ni bila vključena kontrola aktivnosti in izkušenj s samoevalvacijo. Ob ponovnem izvajanju raziskave bi morali že v osnovi razdeliti šole glede na predhodne izkušnje. Omejitev raziskave je tudi število šol oziroma učiteljev v posamezni skupini, ki ni enakomerno. Nekatere šole so namreč zavrnile sodelovanje v aktivnostih, želele pa so rezultate za svoje učence, torej vključenost $\mathrm{v}$ kontrolno skupino.

Zaključimo lahko, da so prepričanja precej stabilna, saj je za spremembo potrebnega veliko časa (Nespor, 1987).
V raziskavi tako nismo uspeli dokazati vpliva spodbujanja procesa samoevalvacije na spremembo prepričanj učiteljev do tega procesa, kar pa je zelo verjetno tudi posledica omejitev raziskave, predvsem kratko obdobje spodbujanja in spremljanja učiteljev.

\section{Zahvala}

Avtorica se zahvaljuje Državnemu izpitnemu centru, ki je tudi omogočil izvedbo raziskave, za podporo pri zbiranju podatkov in analizi.

\section{Literatura}

Brejc, M. in Zavašnik Arčnik, M. (2010). Samoevalvacija $v$ šolah [School self-evaluation] (Interno delovno gradivo). Ljubljana: Državni izpitni center.

Creemers, B. P. M. (1994). The effective classroom. London: Cassell.

Creemers, B. P. M. in Kyriakides, L. (2008). The dynamics of educational effectiveness: A contribution to policy, practice and theory in contemporary schools. Oxon: Routledge.

Demetriou, D. in Kyriakides, L. (2012). The impact of school self-evaluation upon student achievement: A group randomisation study. Oxford Review of Education, 38(2), 149-170.

Fang, Z. (1996). A review of research on teacher beliefs and practices. Educational Research, 38(1), 47-65.

Guskey, T. R. (1986). Staff development and the process of teacher change. Educational Researcher, 15(5), 5-12.

Hattie, J. (2009). Visible learning: A synthesis of metaanalyses relating to achievement. Oxon: Routledge.

Hofman, R. H., Dijkstra, N. J. in Hofman, W. H. A. (2009). School self-evaluation and student achievement. School Effectiveness and School Improvement, 20(1), 47-68.

Hunzicker, J. (2004). The beliefs-behaviour connection: Leading teachers toward change. Principal. Pridobljeno na spletni strani http://www.naesp.org/ resources/2/Principal/2004/N-Dp44.pdf

Japelj Pavešić, B., Svetlik, K. in Čuček, M. (2008). Matematične in naravoslovne naloge za nižje razrede osnovne šole [Mathematics and science assessment items for the lover grades of primary school]. Ljubljana: Pedagoški inštitut.

Kalin, J., Valenčič-Zuljan, M., Peklaj, C., Puklek Levpušček, M. in Pečjak, S. (2007). Vprašalnik o vodenju pouka [Questionnaire on the managment of teaching]. Neobjavljen priročnik.

MacBeath, J. (1999). Schools must speak for themselves. London: Routledge.

MacBeath, J. in McGlynn, A. (2006). Samoevalvacija: Kaj je tu koristnega za šole? [Self-evaluation: What's in it for schools?]. Ljubljana: Državni izpitni center.

Mažgon, J. (2010). (Samo)evalvacija kot raziskovalni proces [Self-evaluation as a research process]. V J. Bukovec (ur.). Samoevalvacija - zakonska zahteva 
ali kazalnik kakovosti [Self-evaluation - a legal requirement or quality indicator] (str. 10-15). Ljubljana: Supra.

Musek Lešnik, K. in Bergant, K. (2001). Samoevalvacija $v$ vzgojno-izobraževalnih organizacijah [Selfevaluation in educational organizations]. Ljubljana: Inštitut za psihologijo osebnosti.

Nespor, J. (1987). The role of beliefs in the practice of teaching. Journal of Curriculum Studies, 19(4), 317-328.

Pajares, M. F. (1992). Teachers' beliefs and educational research: Cleaning up a messy construct. Review of Educational Research, 62(3), 307-332.

Peklaj, C., Kalin, J., Pečjak, S., Puklek Levpušček, M., Valenčič Zuljan, M. in Ajdišek, N. (2009). Učiteljske kompetence in doseganje vzgojno-izobraževalnih ciljev $v$ šoli [Teacher competencies and achieving educational goals in schools]. Ljubljana: Znanstvena založba Filozofske fakultete.

Pirc, T. (2010). Prepričanja učiteljev. Neobjavljena seminarska naloga pri predmetu Poglavja iz pedagoške psihologije na podiplomskem študiju psihologije, Filozofska fakulteta, Univerza v Ljubljani, Ljubljana.

Poljanšek, A. in Bucik, V. (2002). Evalvacija kakovosti [Evaluation of quality]. V Marjanovič Umek, L., Fekonja, U., Kavčič, T. in Poljanšek, A. (ur.). Kakovost $v$ vrtcih [The quality in the kindergartens] (str. 21-35). Ljubljana: Znanstveni inštitut Filozofske fakultete.

Scheerens, J. (2002). School self-evaluation. V D. Nevo (ur.). School-based evaluation: An international perspective. Advances in program evaluation, Volume 8 (str. 35-69). Elsevier Science.

Schildkamp, K., Visscher, A. in Luyten, H. (2009). The effects of the use of a school self-evaluation instrument. School Effectiveness and School Improvement, 20(1), 69-88.

Slavin, R. E., Lake, C. in Groff, C. (2009) Effective programs in middle and high school mathematics: A best-evidence synthesis. Review of Educational Research, 79(2), 839-911.

Tartwijk, J. V., Brekelmans, M. in Wubbels, T. (1998). Students' perceptions of teacher interpersonal style: The front of the classroom as the teacher's stage. Teaching and Teacher Education, 14(6), 607-617.

Vanhoof, J., Van Petegem, P. in De Maeyer, S. (2009). Attitudes towards school self-evaluation. Studies in Educational Evaluation, 35, 21-28.

Warm, T. A. (1989). »Weighted Likelihood Estimation of Ability in Item Response Theory.« Psychometrika, 54, 427-450.

Woolfolk Hoy, A., Davis, H. in Pape, S. J. (2006). Teacher knowledge and beliefs. V P. A. Alexander in P. H. Winne (ur.), The handbook of educational psychology (3. izdaja) (str. 715-737), New York: Routledge.

Zakon o spremembah in dopolnitvah ZOFVI (2008). Uradni list RS, št. 36/2008. 